\title{
Effect of Roasting and Kneading on Antioxidant Activity and Consumer Acceptance towards Asiatic Pennywort Tea
}

\author{
Rungnattakan Ploenkutham ${ }^{1}$, Preeyapa Sripromma ${ }^{1}$, Suksan Amornraksa ${ }^{2}$, Patchanee Yasurin \\ and Aussama Soontrunnarudrungsri ${ }^{1}$ \\ ${ }^{1}$ Department of Food Biotechnology, Faculty of Biotechnology, Assumption University, Bangkok, Thailand \\ ${ }^{2}$ King Mongkut's University of Technology North Bangkok, Bangkok Thailand
}

\begin{abstract}
Nowadays, population have more age and longer life than ancient people which the World Health Organization (WHO) reported that the proportion of the global population will become 'Aging Society' during healthier lifestyles, new advance technologies especially in medical manufacture. This study was aimed to study attitude, behavior and opinion of elderly people towards herbal tea products and to optimize preparation, procedure and process of Asiatic Pennywort tea. According of the study, there are $100 \%$ of Thai people ever consume herbs and herbal tea, they consume as beverage. Half of consumer surveys are no chronic health conditions. Safety of product is the most factors that effect to purchasing decision. The consumers are agree $(73 \%)$ in nutrition value that presented on label as it's clamed on the package. Result from this study shown that roasted and kneading process is highest mean score from consumer's preference $7.07 \pm 1.51(\mathrm{P}<0.05)$ that this method is significantly different in total phenolic content and Ferric reducing antioxidant potential assay but not in DPPH radical scavenging which is highest mean

of second

significantly

level.
\end{abstract}

\section{Introduction}

There are more than 7 billion living humans on earth and the rate of population in each country is increasing that is determined by births and deaths. Asia is the most populous region in the world or $60 \%$ of world population which China is the highest population in the world and follows with India. Rank of Thailand is 19 which have 68 million humans. United Nations Population Fund (UNFPA) reported that the world population has less amount of children population that means elderly population are increasing. The world society will change to Ageing Society. Thailand has chance to be Aging Society because the rate of elderly population is $5.7 \%$ in 1984 and grow up to $9.6 \%$ in 2003 which can expect that Thailand will has elderly population to $14.7 \%$ in 2019 . Elderly definition is an old person who has age more than 60 years old. When entering old age, your senses (taste, smell, touch, vision, and hearing) become less acute and have some trouble in daily life. Herbs and spices have used as a tradition flavor enhancement for each characteristics and their medicinal properties. Herbs and spices are small plant that does not produce woody persistent tissues and has medicinal properties. Herbs and spices can use different parts of plant through processes such as roasting, smoked, fermented or fresh which consume herbs and spices in small amounts can help in bioactivities in human body which can provide health benefits for consumers [1-4]. Thai people have consumed herbal plant as medicines. Herbal plant can use in many ways. Tea is dried leaves of Camellia sinensis plant that usually consume by infuse in hot water. Camellia sinensis plant contains all kinds of great properties, including vitamins (E, C), caffeine and antioxidants. There are several types of tea that made from Camellia sinensis plant. In each types of tea made from different parts such as green tea, black tea, white tea and oolong etc. and different processes such as roasted, air dried and fermentation to create the specific flavors. Herbal tea will be separate from tea. Herbal tea can call "tisanes" (tea zahn) that is commonly used plants from herbs or spices but normal tea use Camellia sinensis plant. Herbal tea is the beverage that can get from using parts of herbs or spices then pass though air dried or fermentation process by pass through soaking, brewing or boiling process as normal tea. There are several herbs that are popular in Thailand and contain several benefits with human health. However, there are the most popular one is 'Asiatic Pennywort' or Centella asiatica or Gotu kola. Thailand has 4 herbs popular products which is Gotu kola (Asiatic Pennywort), Tumeric, Phlai (Zingiber cassumunar) and Black galingale (Kaempferia parviflora Wallich. ex Baker.) that is Thailand's Signature of herbal products. Asiatic Pennywort is important herbal medicinal plant used for many benefits [5]. Ancient people was use in treating all disease for long time such as wound healing 
and eczema.[6-7] Asiatic pennywort contains biological activities compounds for human health, during it contain antioxidant [8-11] that can help in anti-inflammatory[12] and memory enhancing property[10-11]. The main active constituents of Centella asiatica are triterpenes [13], polyphenols[14] and triterpenes [15] such as asiatic acid, asiaticoside, medecasic acid and madecassoside that resistant with antioxidation reaction[16]. Asiatic acid in the triterpenes component responsible for stimulating collagen synthesis of human fibroblasts[17]. Free radicals have been played an important role in ageing capable of damaging many cellular components[18]. Antioxidant will protect oxidative stress reaction. Reactive species (ROS) is low stable molecule, it need an electron to make itself more stable. So, reactive species will bring electron form other cells as a cycle that effect to mitochondria membrane and cell will damage. Protection against free radicals can be enhanced by intake of dietary antioxidants which may be major importance in disease prevention. Therefore, the aim of this project was to study the effect of roasting and kneading on antioxidant activity and consumer acceptance of Asiatic Pennywort tea.

\section{Materials and methods}

\subsection{Study attitude, behavior and opinion of elderly people towards tea products}

There were 100 people participated in this survey. Questionnaire was developed as a tool to gather the information which it was divided into 6 parts which were Part 1: Consumer's behavior about herbs and tea, Part 2: Consumer's attitude and purchasing behavior, Part 3: The factors influence purchasing decision. this part was asked based on their important factors by rating level of importance which used 1 referred to not at all importance and five referred to extremely importance, Part 4: Food consumption behavior based on their knowledge which ask based on their thinking with ability and expectation from products, Part 5: General Information included questions regarding demographic and socioeconomic position of participants such as age, gender, education, house members, income, occupation and chronic health conditions.

\subsection{To optimize preparation, procedure and process of Asiatic Pennywort tea}

\subsubsection{Procedure}

Asiatic Pennywort was purchased from local markets in Bangkok, Thailand. The Asiatic Pennywort was graded that the leave should not have yellow color, bite from insects and free from diseases and pesticides. Fresh Asiatic Pennywort was wash with tap water or rinse before use to clean any soil and dust. The Asiatic Pennywort was packed and kept in refrigerator. There are four formulates with different methods: Kneading \& roasted, Kneading \& not roasted, Not kneading \& roasted and Not kneading \& not roasted. Firstly, the Asiatic Pennywort was separated the leaves out from the stalk. The leave was steamed $90{ }^{\circ} \mathrm{C}$ for 1 minutes. Cool down at room temperature. After that for kneading process, kneading the leaves by using the hands for 5 minutes and left the leaves sample at room temperature for 30 minutes. For roasted process, after cool down the leaves sample was roasted in the pan at $45^{\circ} \mathrm{C}$ for 25 minutes. After that, the leaves were unfolded before put in hot air oven at $80^{\circ} \mathrm{C}$ for 2 hours.

\subsubsection{Sensory testing and sample preparation}

There were 30 elderly people with age between $50-75$ years old participated in the test whose can be male or female. 2 grams of Asiatic pennywort dried leave was put in tea bag. Brew tea with $150 \mathrm{ml}$ of $90{ }^{\circ} \mathrm{C}$ water. The herbal tea bag was soaked for 5 minutes. After that, the herbal tea bag was shaken up and down for 10 times and serve at $65^{\circ} \mathrm{C}-70^{\circ} \mathrm{C}$.

\subsubsection{Chemical analysis}

The Asiatic pennywort tea was determined amount of antioxidant activities. The basic methods were used. The modified Folin-Ciocalteu method[19], DPPH radical scavenging[20] and Ferric reducing antioxidant potential assay[21] were used for evaluating antioxidant activity.

\subsubsection{Antioxidant activity by determine total phenolic content}

The tea sample The tea sample $20 \mu \mathrm{l}$ of $10 \mathrm{mg} / \mathrm{ml}$ was mixed with $1.58 \mathrm{ml}$ of distilled water and $100 \mu \mathrm{l}$ FolinCiocalteu phenol reagent [22]. The samples were stood for 8 minutes 30 seconds at room temperature. Then, add $300 \mu$ saturated sodium carbonate solution and incubated in dark place at room temperature for 30 minutes. After that, the test samples will be observed the optical density (OD) at $765 \mathrm{~nm}$. The data was calculated as microgram garlic acid equivalent $(\mu \mathrm{gGAE} / \mathrm{ml})$. The experiment was done in triplicate[23].

\subsubsection{Antioxidant activity by DPPH radical scavenging activity}

DPPH radical scavenging activity assay[20]. This assay uses to show free radical scavenging activity between DPPH solvent (2, 2-diphenyl -1-picrylhydrazyl) and an antioxidant. Tea sample $2 \mu \mathrm{l}$ was mixed with $2 \mathrm{ml}$ of methanol. Then, DPPH was mixed with $100 \mathrm{ml}$ of methanol. After that, volume of DPPH reagent was varied with the volume of tea sample. The varied sample was leaved in the dark place for 30 minutes. The test samples was measured the optical density (OD) at $517 \mathrm{~nm}$. The result will be expressed as percentage reduction of DPPH. All measurements should analyze in triplication and three replications.

$\%$ reduction of DPPH $=100\left(\frac{A_{0}-A_{C}}{A_{0}}\right)$

Where $\mathrm{A}_{0}$ is the initial absorbance and $\mathrm{A}_{\mathrm{C}}$ is the value for add sample concentration. 


\subsubsection{Antioxidant activity by Ferric Reducing Antioxidant Potential Assay (FRAP)}

The tea sample was used for $2 \mu \mathrm{l}$ mixed with FRAP reagent $1,000 \mu \mathrm{l}$, mix well. The mixture was kept in the dark place at room temperature for 30 minutes. After that, the mixture solution was measured the optical density (OD) at $593 \mathrm{~nm}$. The value will be calculated as mmol $\mathrm{Fe}^{2+} / \mathrm{mg}$ of sample. All measurements should analyze in triplication and three replications. FRAP reagent is mixture between sodium acetate buffer $\mathrm{pH}$ 3.6, Iron chloride and 2,4,6 tripyridyl-s-triazine.

\subsubsection{Statistical analysis}

Data of survey information were processes using SAS version 9.4 (Copyright $\left({ }^{0}\right.$ [2017] SAS Institute Inc., Cary, NC, USA.), Randomized Complete Block Design (RCBD) was applied as experimental design. The data in this experiment was analyzed by using ANOVA (analysis of variance) and Fisher's LSD test $(\mathrm{p}<0.05)$ for multiple comparison. Sensory testing was used about liking score with 9 point hedonic scale.

\section{Result and discussion}

\subsection{Study attitude, behavior and opinion of elderly people towards tea products}

\subsubsection{Demographic information}

There are $100 \%$ of Thai people and nationality who ever consumed herbs and herbal teas. There were male 35\% and female $65 \%$ participated in this survey with age of $51-55$ years old( $48 \%)$, 56-60 years old $(31 \%)$, and $61-65$ years old $(17 \%)$. Most of the elderly stayed with family that had $4-5$ people $(46 \%), 2-3$ people $(33 \%)$, more than 5 people $(11 \%)$ and stay alone $(10 \%)$. They obtained in Bachelor degree (37\%), Lower than high school $(20 \%)$, Master degree or higher(19\%), High school(13\%) and Vocational Certificate or High Vocational Certificate(11\%). The income that they earned in a month is more than $50,000 \operatorname{baht}(25 \%), 20,001-30,000$ baht(21\%), and 10,001 - 20,000 baht(19\%).Most of them are no health conditions or chronic health(39\%), Hypertension(22\%), Dyslipidemia (15\%), Diabetes mellitus(10\%), Obesity and overweight (6\%).

\subsubsection{Consumer behavior}

They consumed Thai herbs (66\%) and consumed as beverage $(42 \%)$, as medicines $(31 \%)$ and eat as food in meals $(27 \%)$. The highest herbal tea that consumers had ever consumed is Chrysanthemum tea $(16 \%)$, Ginger tea (14\%) and Lemon glass tea (13\%). They like to consume They tea from tea bag (34\%) and consume only 1 time in a month $(23 \%)$ which no specific the time to consume herbal tea (45\%), in morning (26\%) and afternoon (21\%). Consumers purchase herbal tea at hypermarket the most
(37\%), and in each time will purchase more than 75 baht $(41 \%)$ for herbal teas. The consumers agreed $(73 \%)$ in nutrition value that presented on label as it's clamed on the package which they think that their body will absorb the nutrients from herbal teas only 50 percent (39\%), 25 percent $(33 \%)$ and 75 percent $(24 \%)$. The reason of consumers consume herbal tea is contain medical benefit $(28 \%)$, make them feel fresh $(23 \%)$ and relaxing $(18 \%)$.

Table 1. The important factor effect on purchasing decision.

\begin{tabular}{|l|c|}
\hline \multicolumn{1}{|c|}{ Factors } & Mean $\pm \mathrm{SD}$ \\
\hline Safety & $4.5 \pm 0.9^{\mathrm{a}}$ \\
\hline Certification & $4.3 \pm 1.0^{\mathrm{b}}$ \\
\hline Nutrition & $4.3 \pm 1.0^{\mathrm{b}}$ \\
\hline Taste & $4.1 \pm 0.9^{\mathrm{bc}}$ \\
\hline Medical properties & $4.0 \pm 1.0^{\mathrm{c}}$ \\
\hline Organic & $3.7 \pm 1.2^{\mathrm{d}}$ \\
\hline Source & $3.6 \pm 1.2^{\mathrm{de}}$ \\
\hline Package & $3.4 \pm 1.2^{\mathrm{ef}}$ \\
\hline NET & $3.3 \pm 1.1^{\mathrm{ef}}$ \\
\hline Brands & $3.2 \pm 1.1^{\mathrm{fg}}$ \\
\hline Trend & $3.1 \pm 1.2^{\mathrm{g}}$ \\
\hline
\end{tabular}

There are significant different between factors effect on purchasing decision $(p<0.05)$. The most important factor is a safety; it means that they like to safe in consume the tea. Next factors are certification, nutrition, and taste. It means that consumer want to consume good products which should has approved from FDA or other warranties due to their age. The taste is also significantly important in the same level as medical properties. Taste relate to perception of consumer that should be good and more benefits together. Moreover, they are not concern in organic product or source, the reason might be the properties contain in herbs are mostly the same benefits. Package, Net weight and Brand of herbal tea products also not affect to purchasing decision. Paper tissue has used for package of tea both inside or outside for tea infusion. Plastic bottle has used as package of tea bottle that easy to consume than tea infusion or when you want to consume tea immediately. Volume or weight is not affected to their decision. Elderly people is not care much in the volume because they are more concern in taste than others factors. From survey found that they are consume only 1 time in a month. Brand and trend are lowest factors for elderly people; it means that famous products, social products or popular products are not effect to their purchasing decision. Nowadays, several was produced and lunched by small group of villagers or they can make it by themselves. 
Table 2: Liking score of Asiatic Pennywort tea from 30 consumers in 10 attributes.

\begin{tabular}{|l|c|c|c|c|c|}
\hline \multicolumn{1}{|c|}{ Process } & Overall liking $^{*}$ & Color & Greeny aroma $^{*}$ & Roasted aroma $^{\text {Sweet }}$ \\
\hline Roasted \& Knead & $7.1 \pm 1.5^{\mathrm{a}}$ & $7.4 \pm 1.3^{\mathrm{a}}$ & $7.1 \pm 1.1^{\mathrm{a}}$ & $6.6 \pm 1.5^{\mathrm{a}}$ & $6.8 \pm 1.2^{\mathrm{a}}$ \\
Roast \& no kneed & $6.9 \pm 1.3^{\mathrm{a}}$ & $7.1 \pm 1.0^{\mathrm{ab}}$ & $6.6 \pm 1.5^{\mathrm{ab}}$ & $6.3 \pm 1.7^{\mathrm{a}}$ & $6.7 \pm 1.4^{\mathrm{a}}$ \\
No roast \& kneed & $6.3 \pm 1.5^{\mathrm{b}}$ & $7.1 \pm 1.3^{\mathrm{ab}}$ & $6.3 \pm 1.6^{\mathrm{b}}$ & $6.3 \pm 1.1^{\mathrm{a}}$ & $6.4 \pm 1.3^{\mathrm{a}}$ \\
No Roast \& no kneed & $6.2 \pm 1.4^{\mathrm{b}}$ & $6.6 \pm 1.4^{\mathrm{b}}$ & $6.2 \pm 1.5^{\mathrm{b}}$ & $6.1 \pm 1.4^{\mathrm{a}}$ & $6.2 \pm 1.7^{\mathrm{a}}$ \\
\hline \multicolumn{1}{|c|}{ Process } & Bitter & Greeny Flavor & Roasted Flavor & Greeny $^{*}$ & Astringent \\
\hline Roast \& kneed & $6.5 \pm 1.3^{\mathrm{ab}}$ & $6.9 \pm 1.6^{\mathrm{a}}$ & $6.7 \pm 1.4^{\mathrm{a}}$ & $6.9 \pm 1.6^{\mathrm{a}}$ & $7.0 \pm 1.4^{\mathrm{a}}$ \\
Roast \& no kneed & $6.8 \pm 1.3^{\mathrm{a}}$ & $6.8 \pm 1.4^{\mathrm{a}}$ & $6.6 \pm 1.3^{\mathrm{a}}$ & $6.7 \pm 1.2^{\mathrm{ab}}$ & $6.7 \pm 1.3^{\mathrm{ab}}$ \\
No roast \& kneed & $6.1 \pm 1.2^{\mathrm{b}}$ & $6.4 \pm 1.5^{\mathrm{a}}$ & $6.2 \pm 1.3^{\mathrm{a}}$ & $6.1 \pm 1.5^{\mathrm{bc}}$ & $6.5 \pm 1.6^{\mathrm{ab}}$ \\
No Roast \& no kneed & $6.3 \pm 1.5^{\mathrm{ab}}$ & $6.5 \pm 1.5^{\mathrm{a}}$ & $6.2 \pm 1.6^{\mathrm{a}}$ & $6.0 \pm 1.6^{\mathrm{c}}$ & $6.1 \pm 1.9^{\mathrm{b}}$ \\
\hline
\end{tabular}

Table 3 : Result of Total phenolic content, Ferric reducing antioxidant potential and DPPH radical scavenging of Asiatic Pennywort tea from different processes.

\begin{tabular}{|c|c|c|c|}
\hline Process & $\begin{array}{c}\text { Total phenolic content } \\
\text { ( } \mu \mathrm{g} \text { GAE/mg dried weight })\end{array}$ & $\begin{array}{c}\mathrm{DPPH} \\
\text { (\% reduction) }\end{array}$ & $\begin{array}{c}\text { FRAP } \\
\left(\mathrm{mmol} \mathrm{Fe} e^{2+} / \mathrm{mg} \text { dried weight }\right)\end{array}$ \\
\hline Roast \& kneed & $62.7 \pm 32.8^{\mathrm{a}}$ & $0.2 \pm 0.0^{\mathrm{b}}$ & $1.6 \pm 0.1^{\mathrm{a}}$ \\
\hline Roast \& no kneed & $28.6 \pm 4.4^{\mathrm{b}}$ & $0.1 \pm 0.0^{\mathrm{b}}$ & $1.7 \pm 0.4^{\mathrm{a}}$ \\
\hline No roast $\&$ kneed & $54.0 \pm 14.7^{\mathrm{ab}}$ & $0.3 \pm 0.1^{\mathrm{a}}$ & $1.4 \pm 0.6^{\mathrm{a}}$ \\
\hline $\begin{array}{l}\text { No Roast \& no } \\
\text { kneed }\end{array}$ & $41.5 \pm 10.7^{\mathrm{ab}}$ & $0.2 \pm 0.0^{\mathrm{b}}$ & $1.9 \pm 0.2^{\mathrm{a}}$ \\
\hline
\end{tabular}

\subsection{To optimize preparation, procedure and process of Asiatic Pennywort tea}

\subsubsection{Sensory analysis}

All attributes were selected from characteristic of sample. There were 30 consumers that participating in the sensory test. There are significant different in overall liking, greeny aroma and greeny aftertaste after taste in different processes of tea $(\mathrm{p}<0.05)$. The significantly most preferred for all attributes is Roast \& kneed process and Roast \& no kneed process, it means that most of consumers are like to consumer roasted processes. Two processes are similar in roasted aroma, sweetness, greeny flavor and roasted flavor. But others all attributes were second level that is color, greeny aroma, greeny aftertaste and astringent of Roast \& no kneed process. The bitterness of Roast \& kneed process is the second level. Moreover, greeny aftertaste has a lowest mean score from consumers which sample No roast \& kneed process and No roast \& no kneed process. From result, roasted greeny aroma and greeny aftertaste, both attributes has lowest mean score in the same process that is not roasted. Roasted also help in bitter taste process can help to reduce greeny attributes. Focusing on (vellarine compound) and astringent (tannin compound) which heating can reduce the level of tannin in winged bean.
Roasted also reduce greeny aroma that occur in the tea products [24-25].

\subsubsection{Chemical analysis}

Herbs are rich in phenolic compounds which are active compound and act as antioxidant properties. Asiatic Pennywort also has active compounds such as triterpenes [13] and polyphenols [14] which contains high total phenolic contents. Total phenolic content was determined with standard garlic acid in term of $\mu \mathrm{g}$ GAE/ mg dried weight. The highest antioxidant activity represented by amount phenolic compound that is $62.7 \pm 32.8 \mu \mathrm{g}$ GAE/mg dried weight which use Roasted \& kneading process. This process is most significant different but not significant different from another 2 processes that is Not roasted \& kneading and Not roasted \& not kneading $(\mathrm{p}<0.05)$. Thermal process is a big influence in active compound which depend on their magnitude, duration and different heating methods. Thermal process lend to degradation of phenolic compounds. For example, roasting barley at $280{ }^{\circ} \mathrm{C}$ for 20 seconds can decrease $8 \%$ of phenol content[26]. For DPPH assay is significantly different in all processes that the highest mean is Not roasted \& kneading process $0.3 \pm 0.1 \%$ DPPH radical scavenging $(\mathrm{P}<0.05)$. Using convection oven drying with spearmint can decrease antioxidant activities 
antioxidant activities approximately $60 \%$ which heating go to inactivate enzyme. [27]. Kneading was used to macerate the cells of leaf which can activate enzymes (mixing of chemical with enzyme) inside the leaf and can be easily being extracted during brewing.[28] For Ferric reducing antioxidant potential assay, there are not significantly different in all processes which the highest mean score is Not roasted \& not kneading process $1.9 \pm$ $0.2 \mathrm{mmol} \mathrm{Fe}{ }^{2+} / \mathrm{mg}(\mathrm{P}<0.05)$.

\section{Conclusion}

The obtained result in this project was used to study habit, attitude and decision of elderly people. The process that will be selected to produce the Asiatic Pennywort tea depend on what is the most concern that if we concern at highest in both testing from sensory analysis from consumer and active compound, Roasted \& kneading process will be selected to produce the Asiatic Pennywort tea. This process is get most significant different in mean scores for sensory, total phenolic content and ferric reducing antioxidant except DPPH radical scavenging has highest mean score from second significant.

\section{Acknowledge}

The authors would like to thank National Research Council of Thailand (NRCT) for the financial support of this research. This work was financially supported by King Mongkut's University of Technology, North Bangkok (Research University Grant No. KMUTNB-61GOV-01-55).

\section{Reference}

1. Ferrucci et al. Measurement of spices and seasonings in India: Opportunities for cancer epidemiology and prevention, Asian Pacific Journal of Cancer Prevention, 1621-1629, (2010)

2. Kaefar M., The role of herbs and spices in cancer prevention Nutritional Science Research Group, National Cancer Institute, Rockville, MD 20892, USA (2008)

3. Johanna L., Spicing up a vegetarian diet: Chemopreventive effects of phytochemicals, The American Journal of Clinical Nutrition, 78 ,579-583 (2003)

4. Tierano L., A reason to season: The therapeutic benefits of spices and culinary herbs, The Journal of Diet and Nutrition, 2, 446-449 (2006)

5. Jacainda J. and Ian D., Pentacyclic triterpenoids from the medicinal herb: Centella asiatica (L.) Urban. Molecules, 14, 3922-3941 (2009)

6. Brinkhaus, B., Lindner, M., Schuppan, D. and Hahn, E. G., Chemical, pharmacological and clinical profile of the East Asian medical plant Centella asiatica. Phytomedicine, 7, 427-428 (2000)

7. Kimura, Y., Sumiyoshi, M., Samukawa, K., Satake N. and Sakanaka M.; Facilitating action of asiaticoside at low doses on burn wound repair and its mechanism. European Journal of Pharmacology 584: 415-421. (2008)

8. Hamid, A. A, Md Shah, Z., Muse, R. and Mohamed, S. Characterisation of antioxidative of Centella asiatica (L) Urban. Food Chemistry 77: 465-469 (2002)

9. Pittella, F., Dutra, R. C., Junior, D. D., Lopes, M. T. and Barbosa N., Antioxidant and cytotoxic activites of Centella asiatica (L) Urb. International Journal of Molecular Science 10, 3713-3721, (2009).

10. Ullah, M. O., Sultana, S., Haque, A. and Tasmin, S. Antimicrobial, cytotoxic and antioxidant of Centella asiatica. European Journal of Scientific Research , 260-264 (2009).

11. Vimala, S., Adenan, M. I., Ahmad, A. R. and Shahdan, R. Nature's choice to wellness: antioxidant vegetables/ulam. Siri Alam dan Rimba, 90-92 (2003).

12. Duke, J. A. (2001). Handbook of Medicinal Herbs. 1st edition. New York:

13. Rattanakom, S.; Yasurin, P. Antibacterial activity, antioxidant activity and chemical profiling of Centella asiatica under different extraction solvents. Orient. J. Chem 31, page 2453-2459 (2015)

14. Zainol A, Hamid S, Yusof R, Muse. Antioxidative activity and total phenolic compounds of leaf, root and petiole of four accessions of Centella asiatica(L.) Urban. Food Chemistry. 81, 575-581(2003)

15. Inamdar, P.K.; Yeole, R. D.; Ghogare, A. B.; de Souza, N. J. Determination of Biologically Active Constituents in Cente-lla Asiatica. J. Chromatogr. A., 742, 127-130 (1996)

16. Ling, A.P.K.; Marziah, M.; Tan, S.E. Triterpenoids distribution in whole plant and callus cultures of Centella asiatica accessions. In Proceeding of the 16th National Seminar on Natural Products, 165-168 (2000)

17. Maquart, F.X.; Bellon, G.; Gillery, P.; Wegrosky, Y.; Borel, J.P. Stimulation of collagen synthesis in fibroblast cultures by a triterpene extracted from Centella asiatica. Connect. Tissue Res, 24, 107-120 (1990)

18. Gulcin, I., Oktay, M., Kirecci, E. and Kufrevioglu, O.I. Screening of antioxidant and antimicrobial activities of anise (Pimpinella anisum L.) seed extracts. Food Chemistry 83: 371-382 (2003)

19. Ragazzi, E.; Veronese, G. Quantitative analysis of phenolic compound after thin-layer chromatographic separation. J. Chromatogr. A. (1973)

20. Brand-Williams, W.; Cuvelier, ME.; Berset, C. Use of a free radical method to evaluate antioxidant activity. LWT-Food Science and Technology. (1995)

21. Benzie, IF.; Strain, JJ. Ferric reducing/ antioxidant power assay: Direct measure of total antioxidant activity of biological fluids and modified version for simultaneous measurement of total antioxidant power and ascorbic acid concentration. Methods Enzymol. (1999)

22. Samtram S. Effect of heat treatments of antinutritional factors and quality of protein in winged bean. Journal of the science of food and agriculture, 39, 267-275 (1987) 
23. Kesornbuakao \& Yasuri.; The Development of Centellaasiatica Extract-Loaded BSA Nanoparticles Production to Improve Bioavailability, Orient. $\mathrm{J}$. Chem., Vol. 32(5), 2425-2434 (2016)

24. Liang, Y., Zhang, L., \& Lu, J. A study on chemical estimation of pu-erh tea quality. Journal of the Science of Food and Agriculture, 85, 381-390 (2005)

25. Zhang, J., Zhang, Z. Z., Zhou, Y. B., Ling, T. J., \& Wan. Chinese dark teas: Postfermentation, chemistry and biological activities. Food Research International 53, 600-607 (2013)

26. Sharma, P. \& Gujral, H.S. Effect of sand roasting and microwave cooking on antioxidant activity of barley. Food Research International, 44, 235-240 (2011).

27. Lim Y.Y., Murtijaya J. Antioxidant properties of Phyllanthus amarus extracts as affected by different drying methods. LWT-Food Science and Technology, 40: 1664-1669 (2007)

28. Naheed $\mathrm{Z}$ et al,. Effect of Rolling, Fermentation and Drying on the Quality of Black tea. Sarhad Journal of Agric, 23, 577-580 (2007). 